\title{
Quantitative variation and selection of esterase gene amplification in Culex pipiens
}

\author{
THOMAS GUILLEMAUD, MICHEL RAYMOND, ANASTASIA TSAGKARAKOU, \\ CLOTILDE BERNARD, PIERRICK ROCHARD† \& NICOLE PASTEUR* \\ Institut des Sciences de I'Evolution, Laboratoire Génétique et Environnement (C.C. 065), UMR CNRS 5554, \\ Université de Montpellier II, F-34095 Montpellier, France and †Laboratoire de Différenciation Cellulaire, \\ Place Pierre Viala, INRA Montpellier, F-34000, Montpellier, France
}

\begin{abstract}
Although descriptions of evolutionary mechanisms are common in the literature, very few studies focus on the possible evolution of the adaptive genes themselves, i.e. their quantitative and qualitative changes. Evolution of insecticide resistance in Culex pipiens is a suitable model for studying such processes. In this species, organophosphorous insecticide resistance can be achieved through the overproduction of esterases that sequester the insecticide, and this overproduction can be caused by gene amplification. It is generally assumed, but never verified, that esterase activity, and therefore resistance, is monotonically related to gene amplification. We have analysed resistance, esterase activity and gene amplification in different laboratory strains and natural populations in order to detect variability and to infer effects of selection on these factors. We have shown that resistance, esterase activity and amplification covary, that insecticide selection is able to increase amplification levels, and that a fitness cost is probably attached to the amplification in laboratory strains, related to the level of amplification. The importance of variation in gene amplification level is discussed and some evolutionary implications are proposed.
\end{abstract}

Keywords: Esterase overproduction, evolution, fitness, gene amplification, resistance.

\section{Introduction}

Previous studies on pesticide resistance have focused generally on the appearance and subsequent dynamics of the resistance genes, but very few have been concerned with the evolution of the resistance genes themselves, i.e. the qualitative or/and quantitative changes they undergo as a result of selection (but see Mutéro et al. (1994); Field et al. (1996); Bourguet et al. (1997); and Guillemaud et al. (1998)).

In Culex pipiens, one mechanism of resistance to organophosphorous insecticides (OP) is the overproduction of two nonspecific carboxylesterases A and B (EC 3.1.1.1). This overproduction is caused either by the coamplification of both A and B esterase structural genes (Rooker et al., 1996; Guillemaud et al., 1997), or by the amplification of the B esterase gene alone (Mouchès et al., 1986; Guillemaud et al., 1997), or else by the up regulation of the A esterase gene expression with no amplification (Rooker et al., 1996). Historically,

*Correspondence. E-mail: pasteur@isem.univ-montp2.fr

(C) 1999 The Genetical Society of Great Britain. the first molecular description of this resistance mechanism focused on overproduction of B1 esterase, present in Californian mosquitoes, which results from the amplification of the $\mathrm{B}$ esterase gene alone (Mouchès et al., 1986). The amplified structure of this gene and the possibility of regulation of gene expression offer a context in which to test several hypotheses concerning the evolution of an adaptive mechanism. In the present study, we analysed the evolution of insecticide resistance of laboratory strains with the B1 amplification in relation to the variations observed in amplification level and esterase activity. We report that amplification, esterase activity and resistance covary, and that the evolution of the amplification level can take place under selection.

\section{Materials and methods}

\section{Mosquito strains and natural populations}

Four laboratory mosquito strains were used in this study.

S-LAB is a susceptible reference strain from California (Georghiou et al., 1966) containing no overproduced 
esterases and no esterase gene amplification (Mouchès et al., 1986).

TEM-R is a strain that has been selected with temephos (an OP) during 14 years. Selections were made each generation on fourth instars at a $30-80 \%$ mortality level. This strain, reared without selection since 1988, is homozygous for the B1 esterase amplification (Raymond et al., 1993).

EDIT is a strain deriving from crosses between the SUTTER-YUBA strain (a field population collected in Sutter-Yuba, California, in 1988 (Ferrari \& Georghiou, 1991)) and the susceptible S-LAB strain. This strain was founded with the offspring of one female SUTTER-YUBA $\times$ S-LAB crossed with one S-LAB male, and selected by single pair-crosses between adults possessing esterase B1 until homozygosity was attained in April 1992. This strain was thus homozygous for a single allele with a given number of $\mathrm{B} 1$ gene copies. This strain was maintained without insecticide exposure.

SEDIT is derived from the homozygous EDIT strain obtained in April 1992. It was selected each generation with a temephos dose killing $>80 \%$ of the larvae.

The known resistance mechanism in the three B1 strains (TEM-R, EDIT and SEDIT) is B1 esterase overproduction. Additionally, another minor resistance mechanism (possibly a reduced penetration) has also been reported in TEM-R (Raymond et al., 1989b), but this resistance is very low.

Three natural populations from the region of Montpellier (southern France) were also used. The St Gély and St Bauzille populations were collected as larvae or pupae in sewage stations in July 1990. The Maurin population was collected in April 1996 as mated females, which were allowed to lay eggs in the laboratory. Mosquitoes were reared until adult, and deep-frozen for further analyses.

Crosses between the B1 strains (EDIT, SEDIT and TEM-R) and the susceptible strain S-LAB were performed in order to obtain heterozygous mosquitoes with a single amplified allele. EDIT and SEDIT mosquitoes were crossed to S-LAB in May 1996, and TEM-R mosquitoes in December 1996. For each B1 strain, between 118 and 165 virgin females were placed in a cage with at least 50 S-LAB males. After 3 days, females were blood-fed and individually isolated into glass vials. The offspring of each female was reared separately at a density of about 100 larvae per $200 \mathrm{~mL}$ of water in the absence of insecticide. Every other day, growing cups were checked and if more than 10 adults had emerged, mosquitoes were frozen in liquid nitrogen. These three sets of $F_{1}$ progeny are referred to as EDITF1, SEDIT-F1 and TEM-R-F1. In each case, the rearing conditions were maintained as constant as possible. The larvae were reared in plastic cups containing tap water complemented with a daily addition of yeast powder. Temperature $\left(22^{\circ} \mathrm{C}\right)$ and light-dark cycles $(14 \mathrm{~h}-10 \mathrm{~h})$ were constant over the whole experimental period.

\section{Insecticide bioassays}

Resistance to temephos was analysed by bioassays according to Georghiou et al. (1966) using plastic cups. Mortality data were analysed using the log-probit program of Ratsira et al. (1996). Dose-mortality responses were considered identical (at $P>0.05$ ) if their parallelism was not rejected at the $5 \%$ probability level and if the confidence limits of the resistance ratio contained the value 1 .

\section{Selection experiment}

Fourth instars deriving from 50 egg-rafts of SEDIT were separated into two batches. The first one, S-SEDIT, was exposed to $0.35 \mathrm{mg} / \mathrm{L}$ temephos during $24 \mathrm{~h}$ (producing a mortality of $80 \%$ ), and the second one, NS-SEDIT, was reared in the same conditions in the absence of insecticide. Twenty-five adults of S-SEDIT and 28 of NS-SEDIT were stored in liquid nitrogen after emergence.

\section{Esterase genotype analysis}

RFLP analyses were carried out on mosquitoes from the three natural populations as described in Raymond \& Marquine (1994). The probe for the esterase $A$ locus is described in Rooker et al. (1996). The probe for the esterase $B$ locus is a PCR product of $2.1 \mathrm{~kb}$. The primers used were:

5'-TGCTGGGACAGGAGTACGTCA- $3^{\prime}$ and 5'-CAGCTTCGGGTCGATCATCAT-3'

The PCR conditions were the same as those described by Guillemaud et al. (1996).

\section{Determination of esterase activity in single mosquitoes}

The protocol used is a modification of that of Ferrari \& Georghiou (1990) or Dary et al. (1990).

Stock solutions Solution A was 0.1 M sodium phosphate pH 7.0 containing $1 \%$ Triton X-100. Solution B was an aqueous solution containing $1 / 20$ of a $6 \times 10^{-2} \mathrm{M}$ $\alpha$-naphthyl-acetate solution diluted in ethanol and $1 / 4$ of solution A. Finally, solution C consisted in $0.8 \mathrm{mg} / \mathrm{L}$ Fast Garnet GBC salt (Fluka, Buchs, Switzerland, 44710).

(c) The Genetical Society of Great Britain, Heredity, 83, 87-99. 
Mosquito preparation Each mosquito was homogenized in $450 \mu \mathrm{L}$ of solution A. Tubes were centrifuged at $10000 \mathrm{~g}$ for $1 \mathrm{~min}$. The supernatant was separated into two parts (1) and (2).

Esterase activity Three dilutions of part (1) of the supernatant were introduced to wells of microplate 1 . The dilution factors in solution A depended on the strain used $(1 / 2,1 / 4$ and $1 / 8$ for S-LAB, 1/20, 1/40 and $1 / 80$ for EDIT and SEDIT, and $1 / 40,1 / 80$ and $1 / 160$ for TEM-R). The final volumes of microplate 1 wells were $75 \mu \mathrm{L}$. After $10 \mathrm{~min}$ of incubation at $25^{\circ} \mathrm{C}$, $100 \mu \mathrm{L}$ of solution $\mathrm{B}$ were added to each well. Microplate 1 was then left at $25^{\circ} \mathrm{C}$ for $30 \mathrm{~min}$, $100 \mu \mathrm{L}$ of solution $\mathrm{C}$ was added to each well and then the microplate was again incubated at $25^{\circ} \mathrm{C}$ for $10 \mathrm{~min}$. The absorbance of each well was measured at $550 \mathrm{~nm}$ using a Spectramax 250 (Molecular Devices, Sunnyvale, CA). The three dilutions were performed in order to obtain at least one measure within the linear range of resolution of the assay (i.e. an absorbance between 0.6 and 1 unit of optical density (OD)). The parameter estimated for each mosquito $i$ is designated as $\mathrm{OD} 550_{i}$.

Material content estimation We studied the range of OD variation of successive dilutions of the supernatant measured in spectral analysis (between 250 and $750 \mathrm{~nm})$. This allowed us to find the wave length $(250 \mathrm{~nm})$ at which OD variations were best correlated with supernatant dilutions. This estimate was highly correlated with dry weight, wing size and protein content estimation; in the comparison with weight and wing size, the correlation was higher in the case of our method than the classic protein assay, and the measurement errors were smaller ( $T$. Lenormand, University of Montpellier II, unpubl. obs.). $150 \mu \mathrm{L}$ of part (2) of the supernatant were distributed to wells of microplate $2 ; 10 \mu \mathrm{L}$ of ethanol were added to each well and the absorbance at $250 \mathrm{~nm}$ was measured. The parameter estimated for each mosquito $i$ is designated as $\mathrm{OD} 250_{i}$.

Estimating the level of esterase activity The increase of esterase activity relative to S-LAB mosquitoes was computed for each mosquito $i$ as:

$$
\operatorname{Activ}_{i}=\left(\mathrm{OD}_{550} / \mathrm{OD} 250_{i}\right) /\left(\mathrm{OD} 550_{S-L A B} / \mathrm{OD} 250_{S-L A B}\right),
$$

where OD250 $-\angle A B$ and OD $550_{S-L A B}$ are the averages of the estimates over all S-LAB individuals measured $(n=48)$. In order to simplify the notation, this parameter will be simply referred to as 'esterase activity' in 'S-LAB' units.

(c) The Genetical Society of Great Britain, Heredity, 83, 87-99.

\section{Determination of $\mathrm{B}$ esterase gene amplification level (AL)}

The method used was an adaptation of Guillemaud et al. (1997) using DNA from a single individual instead of from pooled mosquitoes. The DNA was blotted on nylon membranes and hybridized with the Ace.2 gene (internal control), then with the $B$ esterase gene labelled probes. In order to obtain reading responses within the range of linearity of detection of the $\beta$-imager used (Storm, Molecular Dynamics, Sunnyvale, CA, USA), exposure times between 15 and $24 \mathrm{~h}$ were chosen. On each membrane, three to four S-LAB individuals were included as a control. For each membrane, the $B$ esterase amplification level of individual $i$ was estimated as follows:

$\mathrm{AL}_{i}=\left(\mathrm{B}_{i} /\right.$ Ace.$\left._{2}\right) /\left(\mathrm{B}_{S-L A B} /\right.$ Ace $\left..2_{S-L A B}\right)$,

where $\mathrm{B}_{i}$ and Ace. $2_{i}$ are the quantities of genomic DNA of individual $i$ hybridizing with $B$ esterase and Ace.2 gene probes, respectively, and where $\mathrm{B}_{S-L A B}$ and Ace. $2_{S-L A B}$ are the averages of the estimates over the S-LAB individuals blotted onto the same membrane.

\section{Results}

\section{Insecticide resistance in $B 1$ strains}

Nonselected strains S-LAB, the susceptible reference strain showed no variation in its mortality line between February 1990 (Raymond et al., 1993) and May 1996 (Fig. 1).

The TEM-R strain was bioassayed three times (May 1990, April 1996 and January 1997). For all temephos concentrations, TEM-R was more resistant in 1990. With reference to S-LAB, the resistance ratio (RR) of TEM-R at $\mathrm{LC}_{50}$ varied between 1281 (in 1990) and 365 (in 1996).

EDIT was analysed four times between July 1992 and May 1996. The resistance ratio at $\mathrm{LC}_{50}$ relative to S-LAB decreased continuously and significantly between $1992(\mathrm{RR}=27)$ and January $1995(\mathrm{RR}=17)$, and between August $1995(\mathrm{RR}=15)$ and May 1996 $(\mathrm{RR}=10)$.

Selected strain SEDIT, which was under temephos selection in every generation, was tested four times between January 1995 and April 1996 (in addition to the first bioassay involving the parental strain EDIT in 1992). RR at $\mathrm{LC}_{50}$ decreased slightly between 1992 and January 1995 (from 27 to 22), then it increased significantly between January $1995(\mathrm{RR}=22)$, August 


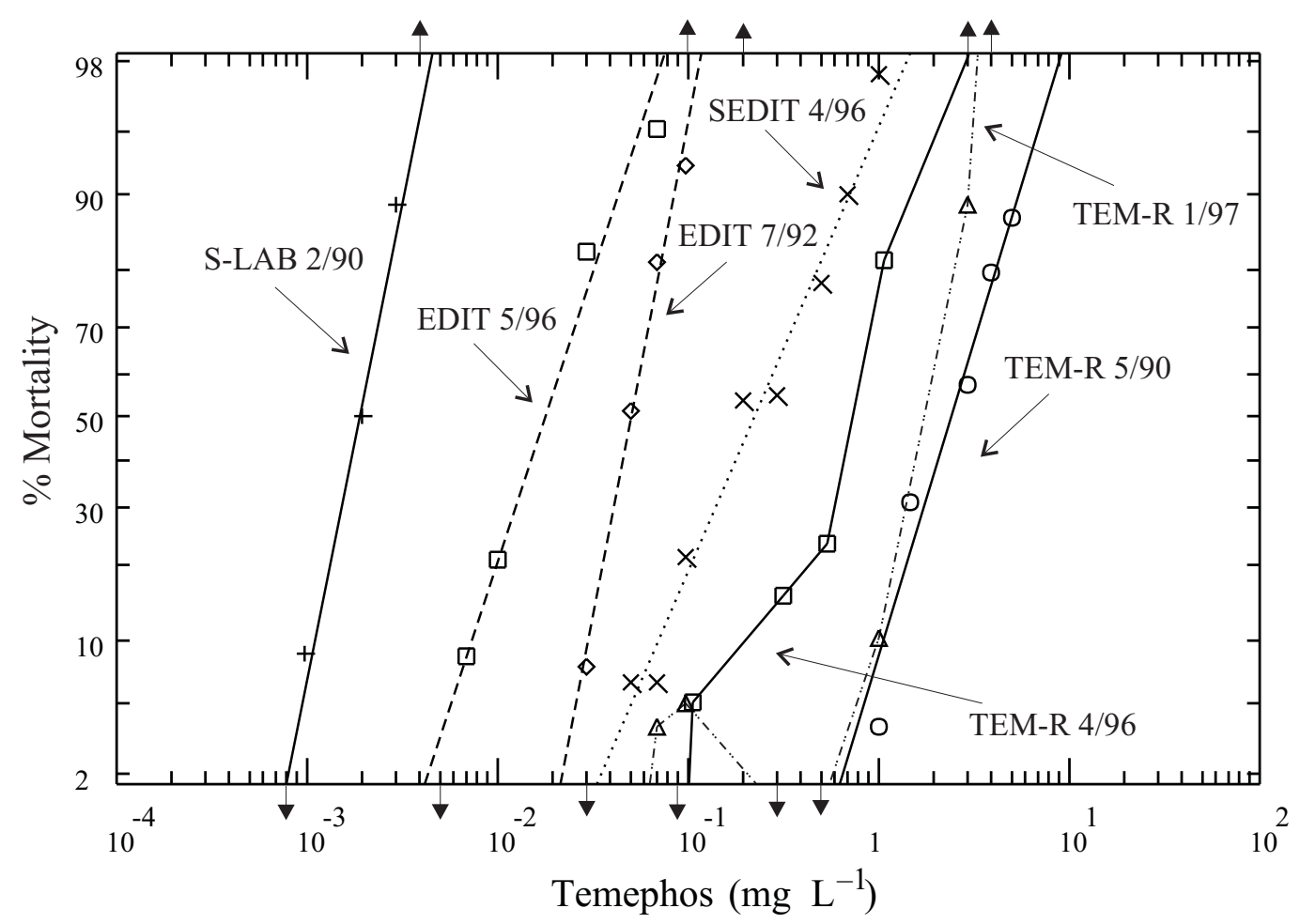

Fig. 1 Evolution of mortality curves of B1 and susceptible strains of Culex pipiens. When a curve could be fitted by a line, this line is shown. Vertical arrows indicate points outside the range of the represented scales.

$1995(\mathrm{RR}=43)$ and November $1995(\mathrm{RR}=225)$, and decreased slightly but significantly between November $1995(\mathrm{RR}=225)$ and April $1996\left(\right.$ at $\left.\mathrm{LC}_{50}, \mathrm{RR}=127\right)$.

At about the time that the $F_{1}$ crosses were performed, the EDIT (in May 1996), SEDIT (in April 1996) and TEM-R (in January 1997) strains presented different mortality curves. Resistance was significantly higher in TEM- $R(R R=1034)$ than in SEDIT $(R R=127)$, and in SEDIT than in EDIT $(\mathrm{RR}=10)$.

\section{Esterase activity in B1 strains}

Esterase activity (EA) was measured on a total of 721 males of the $F_{1}$ progenies. The offspring of 44 females were analysed for EDIT-F1, 35 for SEDIT-F1 and 50 for TEM-R-F1. In addition, $48 \mathrm{~S}-\mathrm{LAB}$ individuals were used as a control. Only male mosquitoes were analysed in order to avoid a possible sex effect on esterase expression.

EA showed extensive variation both between and within $F_{1}$ offspring families (Fig. 2). The three sets of $F_{1}$ mosquitoes have elevated EA compared with S-LAB, as expected.

The variance attributable to parental strains, families and microplates was partitioned by a nested ANOVA (Table 1). In each case one variable was considered fixed whereas the other two were assumed to be varying randomly (Sokal \& Rohlf, 1981). The parental strain effect was highly significant. The mean and variance of EA of each $F_{1}$ set are presented in Table 2. Mosquitoes of TEM-R-F1 had more activity than SEDIT-F1 $\left(F_{1,19}=343.8, \quad P<10^{-5}\right)$, and those of SEDIT-F1 had more than EDIT-F1 $\left(F_{1,23}=12.8\right.$, $\left.P=1.6 \times 10^{-3}\right)$. In each $\mathrm{F}_{1}$ set, the family effect was significant $\left(P<10^{-3}\right)$. The overall data showed a significant microplate effect although it had no significant effect on S-LAB measures $\left(F_{1,46}=0.23, P=0.88\right)$ nor on each $\mathrm{F}_{1}$ set $(P>0.05)$.

\section{Distribution of B1 esterase gene amplification}

The amplification levels (ALs) of the $B$ esterase gene were measured in two sets of experiments. In expt 1, 31 females and between one and five of their male offspring were analysed in SEDIT-F1 and 34 females in EDIT-F1. For TEM-R-F1, the mothers were not available so that only the offspring of 36 families were studied. Amplification was also measured in S-LAB. A total of 605 mosquitoes were analysed. In this experiment, the $B 1$ and $A c e .2$ probes were not purified before hybridization, in order to limit the number of manipulations with the aim of increased standardization. Therefore, a strong background diluted the measures of hybridization of the 
Fig. 2 Histogram of frequency distribution of $\mathrm{B} 1$ esterase activity of $F_{1}$ Culex pipiens from different B1 strains. Note that S-LAB and $F_{1}$ mosquitoes are plotted on different scales.

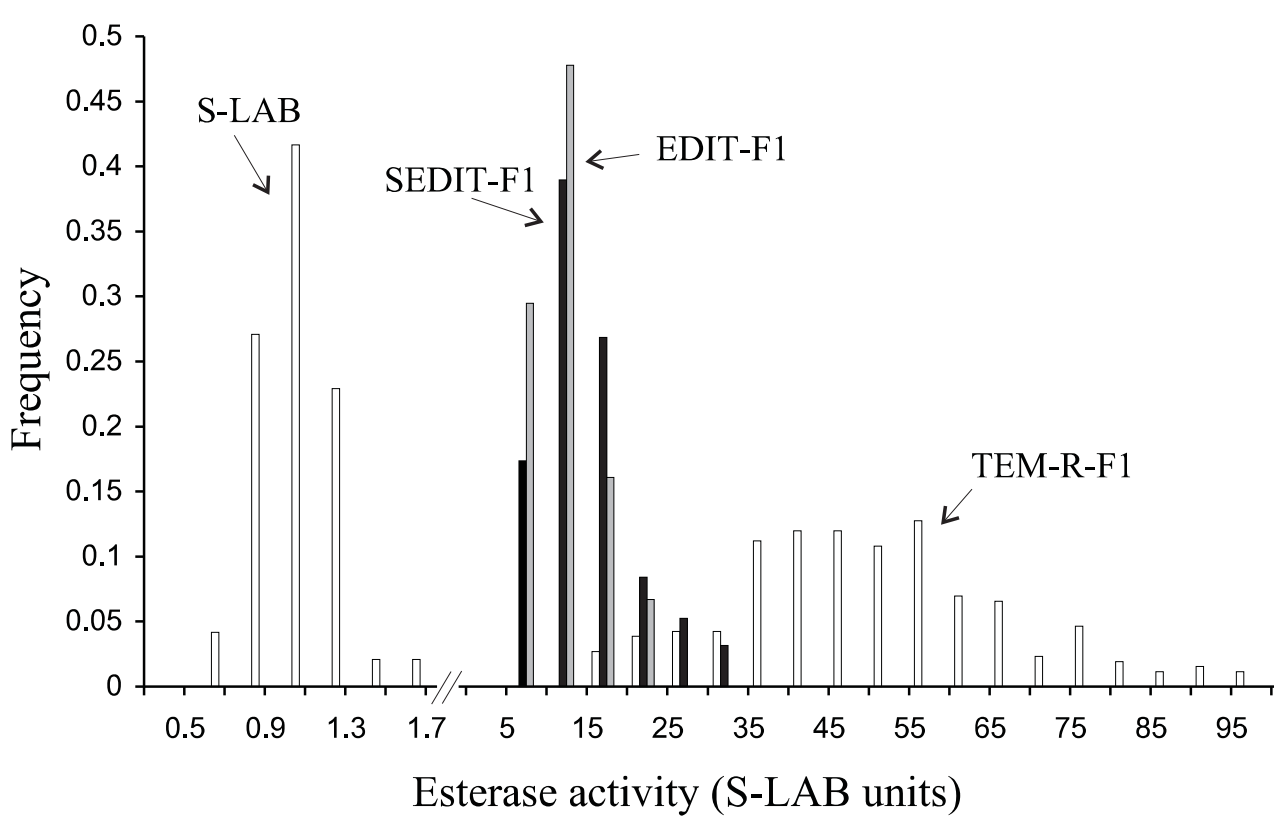

3.86) those of expt 1 when necessary. Most analyses were performed on expt 1 data. When data were calibrated, it is explicitly referred to in the text.

ALs obtained in expt 1 showed extensive variation between and within $F_{1}$ crosses (Fig. 3) and between mothers of the same or different strains. Nested ANOvA (Table 3) shows that the $F_{1}$ strain effect was significant. Mosquitoes of TEM-R-F1 were more amplified than SEDIT-F1 $\left(F_{1,43}=67.11, P<10^{-5}\right)$. SEDIT-F1 mosquitoes were significantly more amplified than EDIT-F1 only in the second experiment $\left(F_{1,45}=6.07, P=2 \times 10^{-3}\right.$,

Table 1 Nested analysis of variance of esterase activities in B1 strains of Culex pipiens. $s$ is the strain factor, $f$ the family factor, $p$ the microplate factor and res the residue

\begin{tabular}{|c|c|c|c|c|c|c|c|c|c|}
\hline \multirow[b]{2}{*}{ Model } & \multicolumn{3}{|c|}{ All } & & & & & & \\
\hline & d.f. & MS & $F$ & & & & & & \\
\hline$s$ & 3 & 86543.3 & $323.3^{* * *}$ & & & & & & \\
\hline$p$ & 32 & 267.7 & $2.1 * * *$ & & & & & & \\
\hline res & 685 & 124.7 & & & & & & & \\
\hline \multirow[t]{3}{*}{ Total } & 720 & 491.2 & & & & & & & \\
\hline & \multicolumn{3}{|c|}{ EDIT-F1 } & \multicolumn{3}{|c|}{ SEDIT-F1 } & \multicolumn{3}{|c|}{ TEM-R-F1 } \\
\hline & d.f. & MS & $F$ & d.f. & MS & $F$ & d.f. & MS & $F$ \\
\hline$f$ & 43 & 46 & $5.36^{* * *}$ & 34 & 90.1 & $3.91 * * *$ & 49 & 942 & $54.35 * * *$ \\
\hline$p$ & 134 & 8.6 & $1.11 \mathrm{NS}$ & 117 & 23 & $1.39 \mathrm{NS}$ & 6 & 17.33 & $0.09 \mathrm{NS}$ \\
\hline res & 46 & 7.7 & & 38 & 16.5 & & 203 & 186.5 & \\
\hline Total & 223 & 15.61 & & 189 & 33.8 & & 258 & 326.1 & \\
\hline
\end{tabular}

$* * * P<0.001$.

(c) The Genetical Society of Great Britain, Heredity, 83, 87-99. 
Table 2 Mean $(m)$ and variance $(V)$ of esterase activity and esterase gene amplification level in each set of Culex pipiens. The sample size $(n)$ is indicated

\begin{tabular}{|c|c|c|c|c|c|c|}
\hline & S-LAB (mothers) & EDIT-F1 (mothers) & SEDIT-F1 & TEM-R-F1 & EDIT & SEDIT \\
\hline \multicolumn{7}{|l|}{ Esterase activity } \\
\hline V & 0.04 & 15.61 & 33.80 & 326.08 & & \\
\hline$n$ & 48 & 224 & 190 & 259 & & \\
\hline Amplification & & \multicolumn{5}{|c|}{ Experiment 2} \\
\hline$m$ & 1 & 2.5 & 3.2 & 5.6 & & \\
\hline$V$ & 0.08 & 0.61 & 0.50 & 1.58 & & \\
\hline \multirow[t]{2}{*}{$n$} & 19 & 23 & 24 & 24 & & \\
\hline & & \multicolumn{5}{|c|}{ Experiment 1} \\
\hline$m$ & 1 & 1.3 & 1.4 & 1.9 & 1.8 & 2.2 \\
\hline$V$ & $2 \times 10^{-4}$ & 0.04 & 0.04 & 0.15 & 0.24 & 0.33 \\
\hline \multirow[t]{2}{*}{$n$} & 85 & 143 & 131 & 160 & 44 & 42 \\
\hline & & \multicolumn{5}{|c|}{ Experiment 1 corrected } \\
\hline$m$ & 1.09 & 2.6 & 3 & 5.6 & 4.9 & 7.1 \\
\hline$V$ & 0.06 & 0.97 & 0.92 & 3.76 & 5.99 & 8.11 \\
\hline$n$ & 85 & 143 & 131 & 160 & 44 & 42 \\
\hline
\end{tabular}

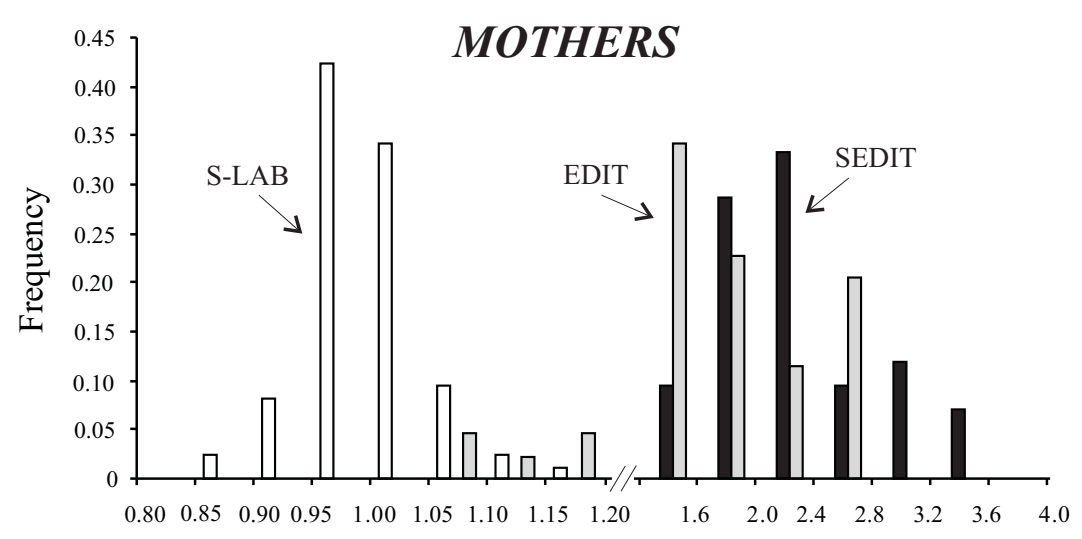

Amplification level (arbitrary units)

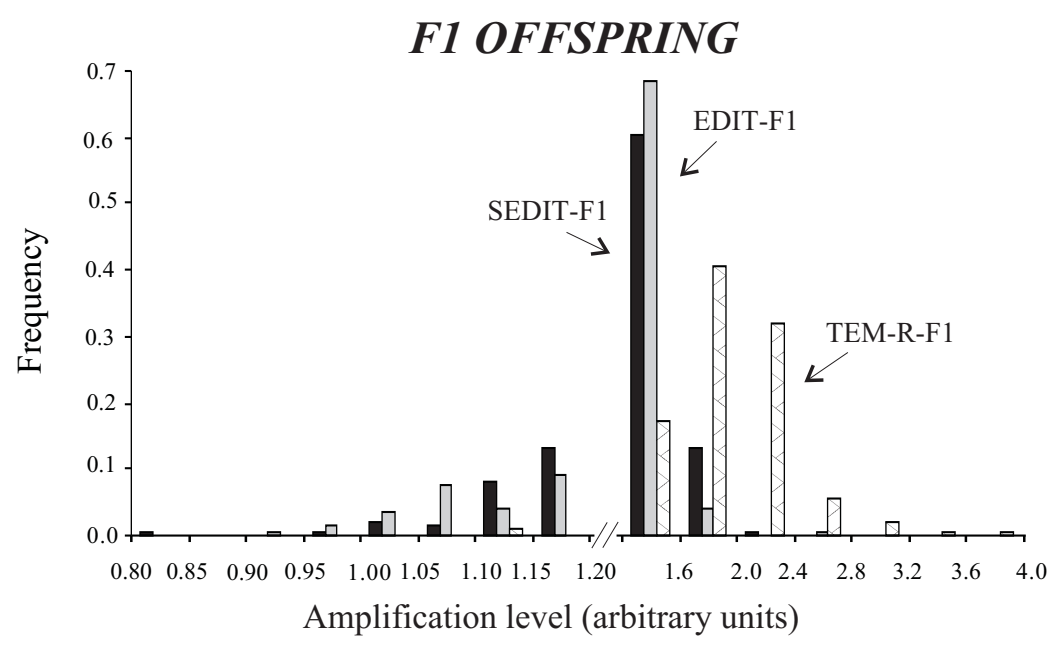

Fig. 3 Histograms of frequency distribution of esterase gene amplification of $\mathrm{F}_{1}$ Culex pipiens from the different $\mathrm{B} 1$ strains (TEM-R mothers were not analysed). Note that two scales are represented on both graphs, in order to obtain approximately the same apparent dispersion for each mosquito set.

(c) The Genetical Society of Great Britain, Heredity, 83, 87-99. 
Table 3 Nested analysis of variance of esterase gene amplification measured in Culex pipiens from expt 1. $s$ is the strain factor, $f$ the family factor, $m$ the membrane factor, and res the residue

\begin{tabular}{|c|c|c|c|c|c|c|c|c|c|}
\hline \multirow[b]{2}{*}{ Model } & \multicolumn{3}{|c|}{ All } & & & & & & \\
\hline & d.f. & MS & $F$ & & & & & & \\
\hline$s$ & 3 & 18.91 & $97.71 * * *$ & & & & & & \\
\hline$m$ & 91 & 0.19 & $4.54 * * *$ & & & & & & \\
\hline res & 444 & 0.04 & & & & & & & \\
\hline \multirow[t]{3}{*}{ Total } & 538 & 0.17 & & & & & & & \\
\hline & \multicolumn{3}{|c|}{ EDIT-F1 } & \multicolumn{3}{|c|}{ SEDIT-F1 } & \multicolumn{3}{|c|}{ TEM-R-F1 } \\
\hline & d.f. & MS & $F$ & d.f. & MS & $F$ & d.f. & MS & $F$ \\
\hline$f$ & 33 & 0.06 & $0.57 \mathrm{NS}$ & 25 & 0.09 & $1.85 \mathrm{NS}$ & 22 & 0.58 & $2.20^{*}$ \\
\hline$m$ & 13 & 0.11 & $4.46^{* * *}$ & 16 & 0.05 & $2.86 * * *$ & 27 & 0.26 & $6.50 * * *$ \\
\hline res & 96 & 0.02 & & 84 & 0.02 & & 110 & 0.04 & \\
\hline Total & 142 & 0.04 & & 125 & 0.04 & & 159 & 0.15 & \\
\hline
\end{tabular}

$* P<0.05, * * * P<0.001$.

in a two-way ANOVA, with strain and membrane as factors). This might be because the membrane effect was not significant in this experiment $\left(F_{1,44}=0.001\right.$, $P=0.96)$. When considering each $\mathrm{F}_{1}$ set, the family effect measured in the first experiment was not significant except for TEM-R-F1. In all the cases, membranes affected the AL measures.

Differences in AL of EDIT and SEDIT mothers were tested in a two-way ANOVA, both strains being present in five membranes. The mother's strain effect was significant in each membrane (global test, $F_{5,69}=11.09$, $P=7 \times 10^{-8}$ ), SEDIT mothers being more amplified than EDIT ones.

Relationships between amplification level in mothers and offspring If selection has no influence upon the distribution of amplification level in offspring and if the AL inheritance is Mendelian, we expect a relationship between $B 1$ esterase gene copy numbers of mothers and offspring. Under these hypotheses, a female with chromosomes carrying $x_{1}$ and $x_{2}$ copies of the Bl esterase gene has a mean amplification level of $\left(x_{1}+x_{2}\right) / 2$. In the $F_{1}$ offspring, the expected $\mathrm{AL}$ of $\mathrm{F}_{1}$ mosquitoes is $\left(\left(x_{1}+x_{2}\right) / 2+1\right) / 2$. So, on average, we have the expected relationship $\mathrm{AL}$ of $\mathrm{F}_{1}=(\mathrm{AL}$ of mother $) /$ $2+1 / 2$. Therefore, we can compare, in each $F_{1}$ set, the observed distribution of family mean ALs of the offspring with their expected values measured by the above formula (Fig. 4). This comparison was performed on calibrated data of expt 1 . The test of mean equality for paired observations is rejected for SEDIT-F1 (Student's $t$-test, $t_{26}=2.2, \quad P=0.037$ ) but not for EDIT-F-1 $\quad\left(t_{33}=1.4, \quad P=0.16\right)$. In SEDIT-F1, the expected values, computed from the observed values of the mothers, are generally larger than the observed values of the offspring ALs. This indicates that alleles with high copy numbers of the $B 1$ esterase gene are less frequent in offspring than predicted (Wilcoxon unilateral signed rank test, $Z=1.83, P=0.034$ ). Figure 4 shows that the expected mean copy number in offspring computed from the observed values of AL in mothers is highly variable in each $\mathrm{F}_{1}$ set, and in the case of EDIT is apparently bimodal. For both sets, the upper range of expected copy number, i.e. classes higher than 4 (i.e. B1 allele in the $F_{1}$ with more than seven copies), is generally not represented in the offspring. This result is related to the fact that no correlation is found between ALs of the mothers and the offspring, neither globally on both SEDIT-F1 and EDIT-F1 $\left(F_{1,59}=0.003, P=0.98\right)$ nor separately in each $F_{1}$ set $\left(F_{1,31}=0.026, \quad P=0.87\right.$, for SEDIT-F1, and $F_{1,24}=$ $1.81, P=0.19$ for SEDIT-F1).

Within-family distribution of amplification level Two families of TEM-R-F1 were more precisely studied. ALs of 53 and 27 mosquitoes from TEM-R-F1-A and TEMR-F1-B were examined on a single membrane in expt 2. TEM-R-F1-A offspring allowed us to test the sex effect on the measurements, because 37 females and 16 males were available. The sex effect proved significant, males having a lower AL than females $\left(F_{1,51}=16.79\right.$, $\left.P<10^{-3}\right)$. The distribution of AL was investigated only on females in both families. In TEM-R-F1-A, a normal distribution is significantly rejected $\left(\chi_{2}^{2}=9.74\right.$, $P=0.008)$. In each family, a few individuals with very low values of $\mathrm{AL}$ were present: two mosquitoes with $\mathrm{AL}$ of 5 and two with AL of 6 in offspring with AL modes of 9 and 8.5 , respectively. 


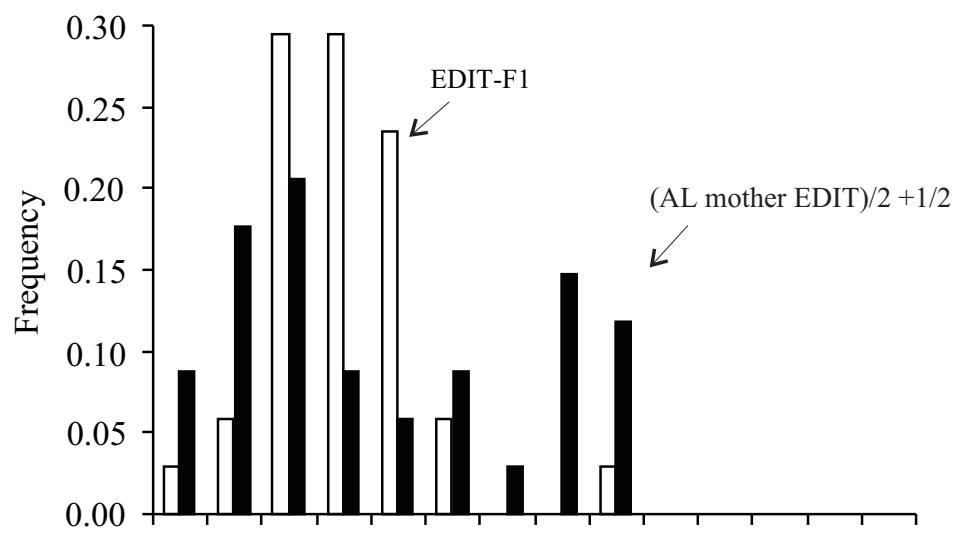

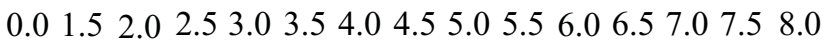

Amplification level

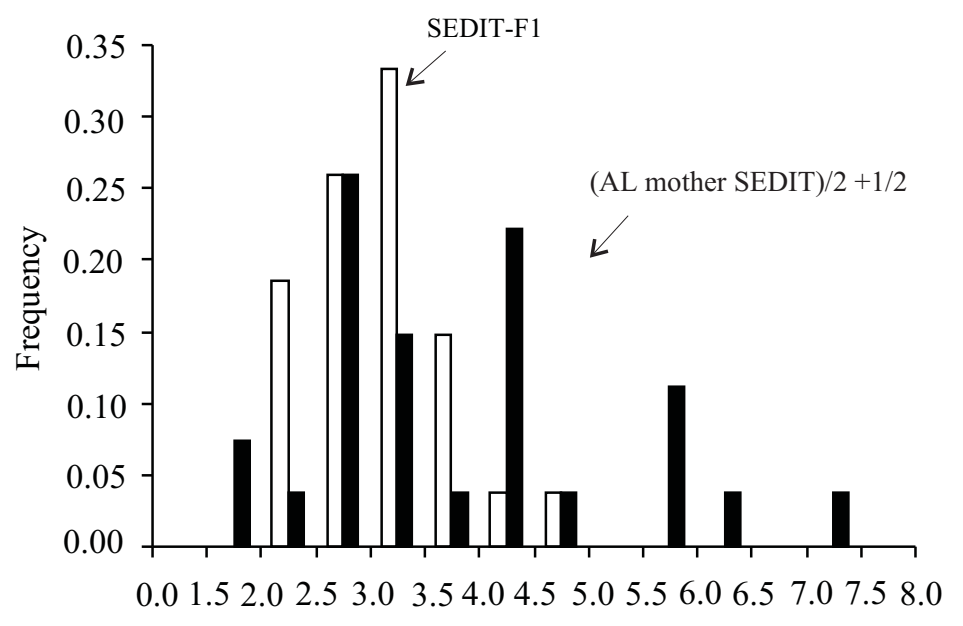

Amplification level
Fig. 4 Histograms of frequency of family mean esterase amplification level in EDIT-F1 and SEDIT-F1 Culex pipiens associated with the expected amplification levels ((AL mothers) $/ 2+1 / 2)$ computed from the mothers' amplification levels (see text for details). These values come from the calibration of expt 1.

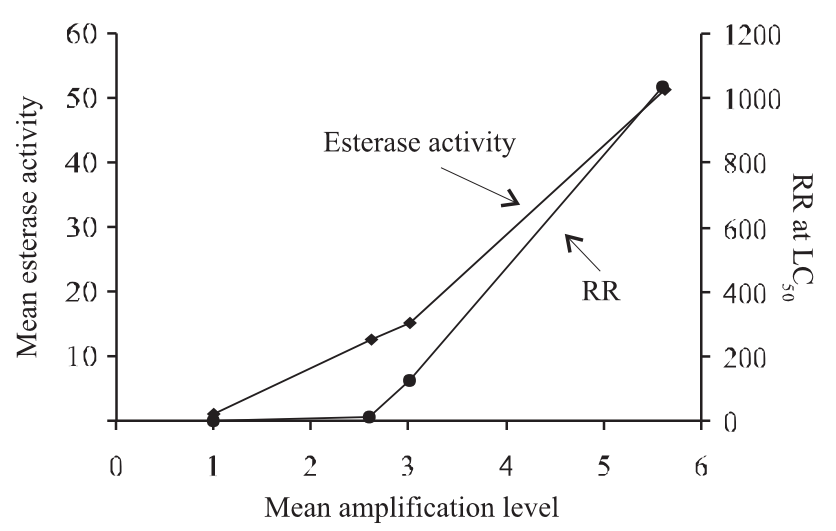

Fig. 5 Relationships for Culex pipiens between resistance ratio at $\mathrm{LC}_{50}$ (for temephos) of parental strains, the mean of esterase activity and amplification level of the three $F_{1}$ sets and the susceptible reference strain S-LAB. Values of amplification levels are from expt 1 calibrated by the results of expt 2 .

\section{Relationships between resistance, B1 esterase activity and $\mathrm{B} 1$ esterase gene amplification}

The three parameters estimated in this study, the resistance ratio (for temephos) of parental strains, the B1 esterase activity and the B1 esterase gene amplification measured in $F_{1}$ sets vary in the same way (Fig. 5).

There is a global correlation $\left(P<10^{-5}\right)$ between the family means of B1 EA and amplification. In each $F_{1}$ set, the relationship is not as clear (Fig. 6). In EDIT-F1 and TEM-R-F1, a negative but nonsignificant relation is found between the family means of ALs and of B1 esterase activities, whereas the SEDIT-F1 set shows a significant negative correlation $(P=0.034)$. This result is probably not an artefact arising from the membrane effect observed in the AL estimation, because when correlations between mean amplification levels and 
Fig. 6 Relationships for Culex pipiens between family mean $\mathrm{B} 1$ esterase activity and family mean amplification level.

Linear regression adjustment lines are also shown. The line in bold corresponds to SEDIT-F1 significant regression, with the associated $r^{2}$ (see text for details). Values of amplification levels are from expt 1 calibrated by the results of expt 2 .

mean esterase activities were computed for each membrane, we observed the same negative trend $(r=-0.09)$ although it is not statistically significant (Global test, Fisher's method, $\chi_{10}^{2}=2.28, P>0.5$ ).

\section{Effect of selection on B1 amplification level in SEDIT}

Amplification levels of two sets of SEDIT mosquitoes reared in the presence (S-SEDIT) and in the absence (NS-SEDIT) of temephos exposure were measured in expt 2. No significant difference was found between the two treatments $\left(F_{1,50}=1.6, P=0.21\right)$.

\section{B4 amplification in the field}

Mosquitoes from natural populations sampled in 1990 and 1996 in southern France were compared. ALs were measured in expt 2 on heterozygous mosquitoes for the A4-B4 amplification. In mosquitoes from 1996, the B4 esterase gene is significantly more amplified (mean 2.7) than in those of 1990 (mean 2.1) $\left(F_{1,24}=4.46\right.$, $P=0.045)$.

\section{Discussion}

\section{Amplification level is variable among strains and families}

A major result of this study is that the amplification level (AL) is variable for a given amplified esterase gene.
Comparisons of the different $F_{1}$ sets have revealed extensive variation of $\mathrm{B} 1$ copy number, as did comparisons of mothers of the three B1 strains. We also detected a family effect on AL in TEM-R-F1. This effect was not influenced by mosquito size and is likely to result from variation in the number of $\mathrm{B} 1$ gene copies, although an environmental effect cannot be excluded despite the precautions taken to minimize it (rearing larvae at low density in standard conditions of food and temperature). It is noteworthy that a family effect was not detectable either in EDIT-F1 or SEDIT-F1. This is possibly because of the relatively low variation in $\mathrm{B} 1$ copy number observed in these $F_{1} s$, or because measurement errors were too high to detect them (as AL in these two sets are much lower than in TEM-R-F1). A family effect on esterase activities was significant in all three $F_{1}$ sets. The results on esterase activity and gene amplification variance are in agreement with those of Ferrari \& Georghiou (1991) who found significant genetic variation of esterase activity among families in backcrosses of a B1 strain.

\section{Amplification level variation is probably caused by a high recombination rate}

In analysing the distribution of AL in crosses TEM-RF1-A and B, we found that a few individuals had a low AL clearly outside the normal distribution. Two hypotheses could explain this observation. First (H1), for each family, this low class of AL may correspond to the segregation of one allele (i.e. a chromosome with a low 
number of $\mathrm{B} 1$ copies) present in the mother. Alternatively $(\mathrm{H} 2)$, this class may represent the result of an unequal crossing-over between the two maternal homologous chromosomes.

Under $\mathrm{H} 1$, the theoretical distribution of $\mathrm{AL}$ in offspring should follow a binomial probability law $\mathrm{B}(n, p)$, with $p=0.5$. This hypothesis is rejected significantly for both families $\left(P<10^{-5}\right.$ and $P<10^{-4}$ for TEM-R-F1-A and B, respectively).

Under $\mathrm{H} 2$, the unequal recombination hypothesis, we have to consider each family separately. For TEMR-F1-A, we might suppose that the mother was homozygous for 17 copies of the Bl esterase gene (or heterozygous for copy numbers around this value). Therefore, a nonrecombinant mosquito would have a measured $\mathrm{AL}=(17+1) / 2=9$, which is observed in the distribution. Mosquitoes with an AL of 5 (i.e. with nine copies of the gene on the maternal chromosome) can be obtained by unequal crossing-over, but in this case we expect also to find recombinants with an AL of 13 (i.e. with 25 copies on the maternal chromosome). Individuals with an AL of 13 were not observed. However, the probability of 'missing' them under a trinomial law $\mathrm{B}(n$, $1-r, r / 2, r / 2)$, with $n$ the number of individuals and $r$ the estimated recombination rate, is $P=0.13$. For TEMR-F1-B, the same kind of argument leads one to consider a mother homozygous for 16 copies of the $B 1$ esterase gene. Recombinants with measured values of AL of 6 can be obtained together with individuals whose $\mathrm{AL}$ is 11. Again, the second type was not present in the distribution. The associated probability of missing them is $P=0.36$. On both families, a global test computed by Fisher's method gives the same information $\left(\chi_{4}^{2}=2.68\right.$, $P=0.61)$.

If the $\mathrm{H} 2$ hypothesis is true, we can estimate a minimum value for the unequal recombination rate within the TEM-R amplification at $4 / 60=6.7 \%$ (between $2 \%$ and $15 \%$ at the $95 \%$ confidence interval). Note that this value is a minimum because recombinants with a copy number close to the normal haplotype would not have been detected. At first glance, this result is in sharp contrast with that of Ferrari \& Georghiou (1991) who found that new B1 copy number variants arose at very low frequency (less than 1 per 500 gametes). However, they only considered as recombinant the mosquitoes displaying an activity falling in the range of nonelevated esterase activity, and therefore could have missed numerous variants. Our result is more in agreement with estimates of Axelrod et al. (1994) with reference to the data of Smith et al. (1990) on CAD gene amplification in hamster cells, i.e. a density of four crossovers per repeat unit using a Poisson distribution model.

\section{Relationships between genotypes and phenotypes}

Some previous studies on $C$. pipiens resistance have suggested the hypothesis that esterase activity, and therefore resistance, were always linked to esterase gene amplification (Pasteur et al., 1984; Ferrari \& Georghiou, 1990, 1991; Raymond et al., 1993; Callaghan et al., 1998). In our analyses, we verified this hypothesis: globally, the more amplified is the Bl esterase gene, the higher is the $\mathrm{B} 1$ esterase activity (in the $\mathrm{F}_{1}$ offspring), and the more resistant is the strain.

A similar result was reported in the aphid Myzus persicae (Field et al., 1988). However, the authors had not undertaken precise quantitative estimations and the amplified genes (E4 and FE4) were different in the strains analysed. In our study, the same $B$ esterase gene (B1) was considered and variations of both gene AL and EA were investigated. The shape of the relationship between mean $\mathrm{AL}$ and mean EA in the $\mathrm{F}_{1}$ mosquitoes and S-LAB shows that the two characters are linearly correlated. However, the relationship between temephos resistance and each of these parameters is not linear. The function that links resistance and EA or AL is more like a threshold one.

\section{Existence of regulatory mechanisms?}

Within strains, AL and EA are not positively correlated. In the three $F_{1}$ sets, we observed a negative correlation which was significant in SEDIT-F1. An experimental bias may explain this pattern. Sex effect can be excluded because only males from each $F_{1}$ set were analysed and AL estimations were independent of mosquito size as we used an internal genomic probe control (the Ace. 2 gene). Therefore it is possible that, at the scale of within-strain variation, an unknown mechanism of esterase expression regulation explains this pattern. Additional work is needed to confirm this hypothesis.

\section{Gene amplification level and selection}

We have seen that amplification level is variable between individuals, and the relationships between amplification level, esterase activity and finally resistance have been established. These two points constitute a necessary theoretical condition for the amplification level to be a factor under selection, and our results indicate that this is indeed the case as insecticide exposures lead to higher copy number of the Bl esterase gene in the selected strain (SEDIT) relative to the nonselected one (EDIT). It is possible that this difference, measured in 1996, may be the result of an increase in SEDIT or a decrease in the 
nonselected EDIT, or both. However, the fourfold increase in resistance of SEDIT between 1992 and 1996 indicates that at least part of the difference in B1 copy number between SEDIT and EDIT was a result of insecticide selection. Additionally, the resistance decreased in the EDIT strain, so that the amplification level of this strain may have evolved too.

The comparison of the number of B4 esterase gene copies in field populations collected in 1990 and 1996 also revealed an evolution of the amplification level. This is the first report of evolution of amplification level of esterase genes in natural populations. However, the level of significance of the difference is low $(P=0.045)$ and needs to be confirmed.

\section{Resistance by gene amplification is subjected to a fitness cost}

Several lines of evidence indicate that resistance and/or the mechanisms involved in the resistance are subjected to a strong fitness cost in the laboratory.

First, the temporal variation of mortality-dose responses showed two kinds of evolution. Resistance has increased globally since 1992 in the selected strain SEDIT. In the absence of insecticide selection, resistance decreased in both EDIT and TEM-R. This contrasts with the results of Raymond et al. (1993) who found no change in the resistance of TEM-R over 1.5 years in the absence of selection. This indicates that this period was not sufficient to detect any variations in resistance.

Secondly, the esterase gene amplification level is not stable with time. In TEM-R, comparison between amplification levels measured in 1990 and 1996 reveals extensive variations. Our estimate of the B1 esterase amplification level in TEM-R (between 5 and 20) is considerably lower than that of Mouchès et al. (1986) or Raymond et al. (1989a), who found amplification levels of 250- and 150-fold, respectively. However, we must interpret these results with caution because the methods used were different.

Thirdly, in SEDIT-F1 mosquitoes, a systematic difference was found between the amplification level of the mothers and that of the offspring. The comparison between mothers and offspring revealed that alleles with a high copy number were under-represented in the offspring. A fitness cost may possibly be involved. Adult and larval mortality of the offspring was not controlled, therefore individuals with a high B1 esterase copy number could have been selected against. Moreover, haplotypes with the high $B 1$ esterase copy number could have been selected against at meiosis or in sperm competition.
The existence of a fitness cost associated with insecticide resistance caused by B1 overproduction has already been documented (Ferrari \& Georghiou, 1981; El-Khatib \& Georghiou, 1985; Raymond et al., 1993) and we showed that such a cost could be associated with B1 esterase amplification level (this study). Therefore, with an estimated recombination rate of more than $5 \%$, we may expect that high ALs could not be maintained in the absence of insecticide selection.

\section{Evolutionary implications}

This study has dealt with the evolution of recent adaptive alleles through the model of insecticide resistance. The effect of selection is strong even after the appearance of these alleles. Some quantitative (amplification level variation) changes in the alleles that alter the phenotype exist and they can be selected for or against. Moreover, the mechanism by which variation in amplification level is achieved appears to be more frequent than previously thought in $C$. pipiens esterase gene amplification.

General models of population genetics that try to infer the outcome of adaptive genes are often based on simple approximations, like the existence of one or two genes with two alleles. Esterase gene amplification is exceptional because a so-called amplified allele (e.g. the B1 amplified allele) is a class of alleles with extensive variation of copy number. In this situation, a population fixed for the presence of an amplified esterase gene must be polymorphic because amplified alleles may have different copy numbers. Moreover, the fact that these amplified alleles could respond to selection for or against by changing their copy number (certainly through unequal crossing-over) may allow such 'fixed' polymorphic populations to adapt rapidly. This situation renders the predictability of allele frequency evolution considerably more complex than in a classic two-allele case. Tabashnik (1990) made a simple model under the assumption of the existence of one, two and three copies of a resistance gene, and showed that the response to selection is different from the predictions of previous models.

Moreover, the well studied effect of fitness cost might be attenuated by the fact that a high recombination rate can allow the rapid adaptation of the allele towards lower copy number. This possibly can explain why cost is still detectable in natural populations and why modifiers of the cost have not been discovered yet in C. pipiens (Chevillon et al., 1997) unlike the case for other species such as Lucilia cuprina (Clarke, 1997). 


\section{Acknowledgements}

We are grateful to G. Pistre and M. Marquine for technical assistance, and to T. Lenormand, D. Bourguet, P. Mollier and J. Lagnel for helpful comments and discussions. Maintenance and selection of EDIT and SEDIT strains between 1992 and 1995 were performed by Edith Dupont, Jérome Sarah and Christophe Louis. This work was financed in part by a GDR $1105 \mathrm{du}$ programme Environnement, Vie \& Sociétés du CNRS, a CEE grant (no. ERBCHRXCT930172), a grant from the Région du Languedoc Roussillon (no. 963223) and by an ACC SV3 (no. 9503037). T.G. benefited from a MESR fellowship (no. 94137). This is contribution ISEM 99.012 of the Institut des Sciences de l'Evolution (UMR CNRS 5554).

\section{References}

AXELROD, D. E., BAGGERLY, K. A. AND KIMMEL, M. 1994. Gene amplification by unequal sister chromatid exchange: probabilistic modeling and analysis of drug resistance data. J. Theor. Biol., 168, 151-159.

BOURGUET, D., LENORMAND, T., GUILLEMAUD, T., MARCEL, V., FOURNIER, D. AND RAYMOND, M. 1997. Variation of dominance of newly arisen adaptive genes. Genetics, 146, 1225-1234.

CALlaghan, A., Gulllemaud, T., MAKATE, N. AND RAYMOND, M. 1998. Polymorphism and fluctuations in copy number of amplified esterase genes in Culex pipiens. Insect Mol. Biol., 7, 295-300.

Chevillon, C., Bourguet, D., Rousset, F., PASteur, N. AND RAYMOND, M. 1997. Pleiotropy of adaptive changes in populations: comparisons among insecticide resistance genes in Culex pipiens. Genet. Res., 70, 195-204.

ClARKE, G. M. 1997. The genetic and molecular basis of developmental stability: the Lucilia story. Trends Ecol. Evol., 12, 89-91.

DARY, O., GEORGHIOU, G. P., PARSONS, E. AND PASTEUR, N. 1990. Microplate adaptation of Gomori's assay for quantitative determination of general esterase activity in single insects. J. Econ. Entomol., 86, 2187-2192.

EL-KhatiB, Z. I. AND GEORGHiOU, G. P. 1985. Comparative fitness of temephos-resistant, -susceptible and hybrid phenotypes of the southern house mosquito. J. Econ. Entomol., 78, 1023-1029.

FERRARI, J. A. AND GEORGHIOU, G. P. 1981. Effects of insecticidal selection and treatment on reproductive potential of resistant, susceptible, and heterozygous strains of the southern house mosquito. J. Econ. Entomol., 74, 323-327.

FERRARI, J. A. AND GEORGHIOU, G. P. 1990. Esterase B1 activity variation within and among insecticide resistant, susceptible, and heterozygous strains of Culex quinquefasciatus (Diptera: Culicidae). J. Econ. Entomol., 83, 1704-1710.

FERRARI, J. A. AND GEORGHIOU, G. P. 1991. Quantitative genetic variation of esterase activity associated with a gene amplification in Culex quinquefasciatus. Heredity, 66, 265272.
FIELD, L. M., DEVONSHIRE, A. L. AND FORDE, B. G. 1988. Molecular evidence that insecticide resistance in peach-potato aphids (Myzus persicae Sulz.): results from amplification of an esterase gene. Biochem. J., 251, 309-312.

FIELD, L. M., HICK, C. A., DEVONSHIRE, A. L., JAVED, N., SPENCE, J. M. AND BLACKMAN, R. L. 1996. Expression of amplified esterase genes in insecticide-resistant Myzus persicae (Sulzer). In: Brown, T. M. (ed.) Molecular Genetics and Evolution of Pesticide Resistance, pp. 72-78. American Chemical Society, Washington.

GEORGHiOU, G. P., METCALF, R. L. AND GIDDEN, F. E. 1966. Carbamate resistance in mosquitoes: selection of Culex pipiens fatigans Wied for resistance to Baygon. Bull. World Health Org., 35, 691-708.

GUILlEMAUD, T., ROOKER, S., PASTEUR, N. AND RAYMOND, M. 1996. Testing the unique amplification event and the worldwide migration hypothesis of insecticide resistance genes with sequence data. Heredity, 77, 535-543.

GUillemaUd, T., MAKATE, N., RAYMOND, M., HIRST, B. AND CALlaghan, A. 1997. Esterase gene amplification in Culex pipiens. Insect Mol. Biol., 6, 319-327.

GUILlEMAUD, T., LENORMAND, T., BOURGUET, D., CHEVILLON, C., RAYMOND, M. AND PASTEUR, N. 1998. Evolution of resistance in Culex pipiens: allele replacement and changing environment. Evolution, 52, 443-453.

MOUCHÈs, C., PASTEUR, N., BERGÉ, J.-B., HYRIEN, O., RAYMOND, M., ROBERT DE SAINT VINCENT, B. ET AL. 1986. Amplification of an esterase gene is responsible for insecticide resistance in a California Culex mosquito. Science, 233, 778-780.

MUTÉRO, A., PRALAVORIO, M., BRIDE, J. M. AND FOURNIER, D. 1994. Resistance-associated point mutations in insecticideinsensitive acetylcholinesterase. Proc. Natl. Acad. Sci. U.S.A., 91, 5922-5926.

PASTEUR, N., GEORGHIOU, G. P. AND ISEKI, A. 1984. Variation in organophosphate resistance and esterase activity in Culex quinquefasciatus Say from California. Génét. Sél. Évol., 16, 271-284.

RATSIRA, A., PRATO, G. AND RAYMOND, M. 1996. WPROBIT (version 1.0). In Licence L93019. Avenix, 34680 St Georges d'Orque, France.

RAYMOND, M. AND MARQUINE, M. 1994. Evolution of insecticide resistance in Culex pipiens populations: the Corsican paradox. J. Evol. Biol., 7, 315-337.

RAYMOND, M., BEYSSAT-ARNAOUTY, V., SIVASUBRAMANIAN, N., MOUChĖs, C., GEORGHIOU, G. P. AND PASTEUR, N. 1989a. Amplification of various esterase B's responsible for organophosphate resistance in Culex mosquitoes. Biochem. Genet., 27, 417-423.

RAYMOND, M., HECKEL, D. AND SCOTT, J. G. 1989b. Interaction between pesticide genes: model and experiment. Genetics, 123, 543-551.

RAYMOND, M., POULIN, E., BOIROUX, V., DUPONT, E. AND PASTEUR, N. 1993. Stability of insecticide resistance due to amplification of esterase genes in Culex pipiens. Heredity, 70, 301-307.

ROOKER, S., GUILlEMAUd, T., BERGÉ, J., PASTEUR, N. AND RAYMOND, M. 1996. Coamplification of A and B esterase genes as a single unit in Culex pipiens mosquitoes. Heredity, 77, $555-561$.

(c) The Genetical Society of Great Britain, Heredity, 83, 87-99. 
SMITH, K. A., GORMAN, P. A., STARK, M. B., GROVES, R. P. AND STARK, G. R. 1990. Distinctive chromosomal structures are formed very early in the amplification of CAD genes in Syrian hamster cells. Cell, 63, 1219-1227.

SOKAL, R. R. AND ROHLF, F. J. 1981. Biometry, 2nd edn. W. H. Freeman and Co., New York.
TABASHNIK, B. E. 1990. Implications of gene amplification for evolution and management of insecticide resistance. J. Econ. Entomol., 83, 1170-1176. 